\title{
What About a 'Custom Abutment'?
}

\author{
Bora Bagis* and Oytun Kutsal \\ Faculty of Dentistry, Department of Prosthodontics, Izmir Katip Çelebi University, Turkey
}

Implants are one of the most versatile tools in dentistry and have been shown their usefulness in many studies. Increased confidence in dental implants has expanded their use in many cases. High survival rates of implant restorations were reported in the dental literature, and their value is regularly proven [1]. Different implant designs and new materials for implants are being released. Within all this rush, new abutment designs are showing up, too.

Years of experience in implant dentistry showed that stock abutments are viable option for implant restorations. But with the development of technology, new sets of abutments have arisen: custom abutments. These abutments can be privately fabricated for every patient easily, even with different materials regarding the patients' needs. They can be fabricated with CAD/CAM milling technique in a very short time. But this new development raises some questions for dentists. Are custom abutments viable? Are they better than stock abutments? Is it a necessity, or are they just expensive replacements for stock abutments for no reason? Should dentists use custom abutments?

The biggest problem with stock abutments was that tissue compatibility could have not been achieved easily, and the stock abutments are insufficient for the angulated implants. But custom abutments are unique and made for individual patients. In particular, with temporary custom abutments used for tissue shaping, implantsupported restorations can be given an emergency profile during the recovery period of the implantation. Interdental/interimplant papillae may also be obtained with the shaped tissue, which is produced by custom abutment while maintaining the aesthetic appearance. These treatments also increase both cleanability and prevent the food residues. In such cases, custom abutment will make prosthodontists' work easier $[2]$.

Stock abutments are generally sold with a metallic option, such as titanium. Custom abutments can be made with different combinations of zirconia and lithium disilicate with titanium. These abutments can be fabricated in dental offices by using CAD/CAM devices. Implant and abutment connection is managed with the titanium base and the aesthetic part is luted with adhesive resin cements. Especially in the aesthetic region, metal reflection adversely affects the aesthetics. In these implant-supported full ceramic restorations, the abutment made of lithium disilicate or zirconia may eliminate the possible metal reflection.

Alternatively, the custom-made titanium abutment can be colored by anodization. Due to the gingival region's colorization is pink, with the yellow/gold coloration of the crown region, this reflection problem might be minimized [3].

There are also custom abutments made entirely from chromium cobalt or zirconia. Studies conducted with abutments made entirely from zirconia showed that zirconia abraded the hex region of titanium, and after a while, the harmony deteriorated [4,5]. Although Ti-base abutment does not have this kind of problem, the connection between titanium and zirconia brings some questions in mind. Their tightness and full retention are controversial.

When the edentulous space is larger for a single implant but not enough for two, restoration of the implant with the stock abutment is generally insufficient. It is unable to fully support the crown, and due to the contours of the crown, the cantilever effect is created on the abutment. In this case, the wide space can be restored with a mechanically well-supported crown restoration by a wide output profiled custom abutment.

The biggest problem with custom abutments is that the implantabutment connection is not "original." It is questionable whether these subsequent hex connections are fully compatible with the implants. The manufacturing of these surfaces may only be prepared with calibrated and high precision devices. The "pre-milled abutment" blocks, which some implant companies are using, bring a new perspective to custom abutments. Pre-milled blocks allow us to use custom abutments with original hex connections. Again, these abutments can also be painted by anodization, and aesthetic problems can be prevented [6].

Day by day, custom abutment finds its place in the standard treatment protocols. Implant companies are started to make their own pre-milled blocks for producing custom abutments. Due to all these advantages, dentists have gradually started to move towards to use custom abutments in daily routine. After all, dentists should not forget the risks of incompatibility of custom-made abutments. More data is needed to give a strong comment on custom abutments, but they are promising in some complicated cases.

\section{References}

1. Zembic A, Kim S, Zwahlen M, Kelly JR (2014) Systematic review of the surviva rate and incidence of biologic, technical, and esthetic complications of single implant abutments supporting fixed prostheses. Int J Oral Maxillofac Implants 29: 99-116. [Crossref]

2. Kan JY, Rungcharassaeng K (2003) Interimplant papilla preservation in the esthetic zone: a report of six consecutive cases. Int J Periodontics Restorative Dent 23: 249259. [Crossref]

3. Wadhwani CP, O'Brien R, Kattadiyil MT, Chung KH (2016) Laboratory technique for coloring titanium abutments to improve esthetics. J Prosthet Dent 115: 409-411. [Crossref]

4. Klotz MW, Taylor TD, Goldberg AJ (2011) Wear at the titanium-zirconia implantabutment interface: A pilot study. Int J Oral Maxillofac Implants 26: 970-975. [Crossref]

${ }^{*}$ Correspondence to: Bora Bagis, Faculty of Dentistry, Department of Prosthodontics, Izmir Katip Çelebi University, Turkey, E-mail: bbagis@yahoo.com

Received: September 20, 2018; Accepted: September 26, 2018; Published: September 28, 2018 
Bagis B (2018) What About a 'Custom Abutment'?

5. Stimmelmayr M, Edelhoff D, Güth JF, Erdelt K, Happe A, et al. (2012) Wear at the titanium-titanium and the titanium-zirconia implant-abutment interface: a comparative in vitro study. Dent Mater 28: 1215-1220. [Crossref]
6. https://www.straumann.com/en/professionals/products-and-solutions/implant-borneprosthetics/pre-milled-abutment-blanks.html.

Copyright: $(\mathcal{C} 2018$ Bagis B. This is an open-access article distributed under the terms of the Creative Commons Attribution License, which permits unrestricted use, distribution, and reproduction in any medium, provided the original author and source are credited. 